\title{
The Effect of Information Disclosure Quality on Stock Price Crash Risk: Evidence from Listed Companies in China
}

\author{
Hongbo Zhang, Chun Hyun Nam \\ The University of Suwon, Hwaseong, Korea
}

From most prior studies, the effect of information disclosure quality on stock price crash risk is negative. However, using a large sample of Chinese firms for the period of 2001-2012, we find a nonlinear U-shape link between information disclosure quality and crash risk. Using synchronicity risk indicator $R^{2}$ as the proxy of information transparency, we find that opaque firms, as well as excessive transparent firms, are both more prone to stock price crashes. We identify one possible mechanism through which excessive transparency increases crash risk: excessive volatility augments volatility feedback effect and overreaction effect and then increases crash risk.

Keywords: crash risk, information disclosure, $R^{2}$, transparency

\section{Introduction}

Traditional theory views stock price crash risk to be driven by asymmetric information. Large literatures investigate the relation between firm's information transparency and stock price crash risk. Their common point of departure is the notion that greater transparency and more complete revelation of firm-specific information should reduce crash risk (Jin \& Myers, 2006; Bleck \& Liu, 2007). However, this view overlooks two points. First, the relation between opacity and crash risk may be not linear. That is to say, excessive transparent information disclosure may also increase crash risk. Second, an endogeneity bias may appear with popular information transparency measures based on firm's financial reports since management can select how to disclose information in financial reports.

Our investigation is firstly motivated by possible nonlinear relation between information opacity and crash risk. Financial economist and accountant have long viewed stock price changes tied to new information about firms' prospects. Excessive transparent information disclosure includes much noise and means more volatile price movements. The conjecture that excessive transparency may increase crash risk due to two effects: volatility feedback effect and overreaction effect. Volatility feedback effect shows that bad news have greater impact on volatility than good news (French, Schwert, \& Stambaugh, 1987; Campbell \& Hentschel, 1992), thus generating negative skewness. Overreaction effect shows that investors overreact to new positive information, which cause a possible price bubble and then sow the seeds of crash risk (De Bondt \& Thaler, 1985). These two effects together increase crash risk with excessive transparent information.

\footnotetext{
Hongbo Zhang, associate professor, Ph.D. candidate, School of Economic and Business, The University of Suwon. Email: sdzhanghb@163.com.

Chun Hyun Nam, professor, Ph.D., School of Economic and Business, The University of Suwon.
} 
Our investigation is also motivated by the endogenous link between information opacity and crash risk. Recent researches show that the lack of information transparency increases future crash risk by enabling managers to hide and accumulate bad news (Hutton, Marcus, \& Tehranian, 2009; Jin \& Myers, 2006; Kim, Li, \& Zhang, 2011a; 2011b). Extensive literatures measure transparency (or opacity) of information using several kinds of proxies and a popular one is earnings management, such as discretionary accruals, earnings aggressiveness, loss aversion, earnings smoothing, and so on (Dechow, Sloan, \& Sweeney, 1995; Bhattacharya, Daouk, \& Welker, 2003; Hutton et al., 2009). Such kind of proxy is based on firm's financial reports, especially financial statements. We query whether the selective information disclosure behavior is dependent on firm's heterogeneity. If some heterogeneity involves crash risk, it will bring the endogenous link between information opacity and crash risk. Using the proxy based on financial statements could not avoid the endogeneity issue. We use market synchronicity $R^{2}$ as the proxy of information disclosure quality in this study, which is a market evaluation of firm-specific information opacity.

Building on the above arguments and evidence, we conjecture two counter hypotheses: (1) Information disclosure quality decreases future stock price crash risk. This conjecture is supported by bad news hoarding leads to stock price crashes; and (2) Information disclosure quality increases future stock price crash risk. This conjecture is supported by excessive transparent information increases volatility, volatility feedback effects and overreaction effect. The above two effects may both exist and it needs investigation.

Chinese stock market provides a good sample to test the above two counter hypotheses. Firstly, Chinese stock market is an emerging market with high crash risk. Popular Chinese academic research considers that crash risk originates from insufficient regulations on firms' information disclosure, especially no enough punishments on opaque information disclosure, which makes it easier for firms to take bad news concealment actions. Secondly, Chinese stock market is an emerging market with a large number of individual investors and strict short-sale constraints. About $80 \%$ of circulation market value is owned by individual investors in China according to the statistics provided by Shanghai Stock Exchange. Individual investors are less skilled and more vulnerable to impact of surrounding environment which includes information and sentiment around. Strict short-sale constraints strengthen overreaction effect. Excessive transparent information causes unnecessary worries about firms' prospectus when bad news arrives and causes over optimism when good news arrives. Both of them increase crash risk.

This paper contributes to the literature in two ways. First, to our knowledge, this is a first study to show a nonlinear relation between information disclosure and crash risk, which adds to the recent stream of research on the sources and mechanisms of crash risk. Second, our research proposes an exogenous proxy to measure the impact of information disclosure quality on crash risk. We avoid possible endogenous link between information opacity and crash risk with those proxies based on firms' financial reports.

The remainder of the paper is structured as follows. Section 2 conducts a review of the related literature and presents our central predictions. Section 3 describes the data and the measurement of key variables. Section 4 presents the empirical analysis. Section 5 presents our conclusions.

\section{Literature Review and Hypothesis Development}

The link between information asymmetry and crash risk has been extensively discussed in the literature. When less firm-specific information is publicly available, information asymmetry becomes more severe, stock market synchronicity and crash risk both increase. 
Several mechanisms could generate crash risk, or more generally, negative skewness in returns. For example, it is well-known that a wide range of incentives, such as compensation contracts, career concerns, and empire building, motivate managers to conceal adverse operating income (Ball, 2009; Kothari, Shu, \& Wysocki, 2009). If a firm's manager withholds and accumulates negative information for an extended period, the firm's share price will be severely overvalued, thereby creating a bubble. When the accumulated negative information reaches a tipping point, it will be suddenly released to the stock market, all at once, resulting in the bubble bursting and a stock price crash (Hutton et al., 2009; Jin \& Myers, 2006). Moreover, hiding bad news prevents investors and the board of directors from discerning negative net present value (NPV) projects at an early stage and forcing managers to take timely abandonment actions. As a result, the bad performance of negative NPV projects accumulates and eventually materializes, which results in asset price crashes (Bleck \& Liu, 2007).

Other sources of negative skewness focus on investors with heterogenous beliefs and short-sale constraints. Trading among investors who have different opinions could reveal the private signals of others and move prices even in the absence of new fundamental information (e.g., Romer, 1993). In Hong and Stein (2003), this process, combined with short-sale constraints, imparts an asymmetry in which market declines differentially reveal the private signals of relatively pessimistic investors. Such revelation could lead other investors to downgrade their assessments of a firm's prospectus, thereby reinforcing the decline.

Our empirical tests, however, are firstly motivated by both models set by Jin and Myers (2006): volatility feedback effect and overreaction effect. Asymmetry character of stock returns was first proposed by Mandelbrot (1963) and it has been discussed extensively. Large studies show that bad news causes greater volatility than good news. The reason behind it may be feedback effect. Volatile price movements could cause investors to reassess market volatility and increase required risk premia. An increased risk premium reduces equilibrium prices, which reinforces the impact of bad news but offsets the impact of good news, thus generating negative skewness in return and then increasing crash risk (e.g., French et al., 1987; Campbell \& Hentschel, 1992). In recent 30 years, we find massive evidence for market inefficiency and one of them is overreaction effect. Prior studies show that in violation of Bayes' rule, most people tend to "overreact" to unexpected and dramatic news events (De Bondt \& Thaler, 1985). What's more, investors tend to overreact to positive information and this also increases crash risk.

Information disclosure is the main channel to reduce the information asymmetry. Information disclosure indicates that the firm's management authorities release information to shareholders, creditors, and other stakeholders publicly, including compulsory disclosure items required by regulatory rules and additional voluntary disclosure items. Since the U.S. Securities and Exchange Commission (SEC) formally proposed the term "transparency" in its designated international accounting standards IASC "core standards of high quality assessment” in 1996, "company transparency” gradually replaces the level of information disclosure and has become the mainstream of the research area. However, information disclosure quality or transparency is a relatively abstract concept and no global features can be directly observed and measured. Researchers can only select some of the dimensions or local features as a proxy for the overall information disclosure. Commonly used proxy variables include six categories: (1) the amount and frequency of information disclosure (Miller, 2002; Botosan, 1997; Lang \& Lundholm, 1993; 1996); (2) specific information disclosure projects, such as the accuracy of earnings forecasts from the management authority (Coller \& Yohn, 1997); (3) specific commitments or behaviors, such as the use of higher quality accounting standards (Bartov \& Bodnar, 1996; 
Leuz \& Verrecchia, 2000); (4) security analyst intensity which means the number of securities analysts tracking at a particular company (Lang \& Lundholm, 1996); (5) earnings management, such as discretionary accruals, earnings aggressiveness, loss aversion, earnings smoothing (Dechow et al., 1995; Bhattacharya et al., 2003; Hutton et al., 2009); and (6) information disclosure index developed by authority. Some index, such as Transparency \& Disclosure score developed by Standard \& Poor's and CIFAR index developed by the Center for International Financial Analysis and Research (CIFAR), is mainly used to measure the transparency of the country or region. Some index, such as information disclosure index developed by Corporate Governance Research Center in Nankai University, and information disclosure assessment published by Shenzhen Stock Exchange, is used to measure the transparency at firm level.

In addition, the link between opacity and $R^{2}$ has been extensively discussed since Roll (1988) first proposed $R^{2}$ from a modified index-model regression as a measure of the revelation of firm-specific news. Their common point of departure is the notion that greater transparency and more complete revelation of firm-specific information should reduce $R^{2}$ (Morck, Yeung, \& Yu, 2000; Piotroski \& Roulstone, 2004; Durnev, Morck, Yeung, \& Zarowin, 2003). We adopt $R^{2}$ as the proxy for information opacity.

In an effort to isolate the effects of information disclosure quality, our specifications also include a number of control variables. These control variables include the relatively fixed firm characteristics, such as size, MB (market value to book value), financial leverage, operating performance, and shareholders' concentration. It has been documented by Chen, Hong, and Stein (2001), Hutton et al. (2009), and An and Zhang (2013) that size, MB, financial leverage, operating performance, and ownership significantly impact crash risk.

This study intends to provide comprehensive evidence on the relation between information disclosure quality and crash risk. Specifically, it tests the following hypotheses in an alternative form:

H1: All else being equal, information disclosure quality is negatively associated with stock price crash risk.

$\mathrm{H} 1$ predicts, in other words, a positive correlation between information opacity and crash risk. It implies that improving information disclosure transparency can reduce crash risk. The prediction of the negative relation between information disclosure transparency and crash risk is based on the incomplete information framework set by Jin and Myers (2006). It is supported by bad news hoarding leads to stock market price crash.

H2: All else being equal, over excellent information disclosure quality is positively associated with stock price crash risk.

$\mathrm{H} 2$ is contrary to $\mathrm{H} 1$ and it implies that improving information disclosure transparency can increase crash risk. The prediction of the positive relation between information disclosure and crash risk is based on higher volatility caused by excessive transparency, volatility asymmetry and feedback effect and overreaction effect.

On the surface, the above two hypotheses are contradictory but maybe they both exist in practice. That indicates a nonlinear link between information disclosure quality and crash risk. Or to say, there is a turning point for information disclosure. If initial information disclosure is opaque, then improving information disclosure can reduce crash risk and $\mathrm{H} 1$ dominates the market. However, if initial information disclosure is good enough, then further improving information transparency can bring much noise and increase crash risk. H2 dominates the market. 


\section{Research Design}

\section{Data Source and Sample}

Information disclosure assessment for listed firms is a special service provided by Shenzhen Stock Exchange since 2001. Our sample period begins in 2001, which is as far back as we can get the official information disclosure assessments. Our sample period ends in 2012 which is the last year we have manually completed collection for information disclosure assessments data.

To construct other variables, we combine daily stock return data and annual financial data for all Shenzhen Stock Exchange listed A-share firms, from China Stock Market Accounting Research (CSMAR). We begin with all firm-years on CSMAR between 2001 and 2012. We do not include firm-years with insufficient financial data and then get a sample of 9,282 firm-years on 1,559 firms. We exclude firm-fiscal years with fewer than 30 trading days of stock return data and those firm-IPO years without assessments. Finally, we are left with a final sample of 8,395 firm-years on 1,410 firms.

\section{Measuring Firms’ Crash Risk}

This study employs two measures of crash risk, which are constructed following previous studies in the crash risk literature.

The first measure of crash risk is the negative coefficient of skewness (NCSKEW) proposed by Chen et al. (2001). Specifically, we calculate NCSKEW for a given firm in a fiscal year by taking the negative of the third moment of firm-specific daily returns for each sample year, and dividing it by the standard deviation of firm-specific daily returns raised to the third power. Thus for each firm $j$ over any fiscal year period $t$, we compute NCSKEW as:

$$
N C S K E W_{j, t}=-\left[n(n-1)^{3 / 2} \sum R_{j, t}^{3}\right] /\left[(n-1)(n-2)\left(\sum R_{j, t}^{2}\right)^{3 / 2}\right]
$$

where $R_{j, t}$ represents the sequence of demeaned daily return to stock $j$ during period $t$ and $n$ is the number of observations on daily returns during the period. Since the special trading mechanism of $10 \%$ daily price changes limit in Chinese stock market, we calculate five trading days rolling returns. These "daily returns" are, more precisely, actually log changes in price. We use log changes as opposed to simple daily percentage returns because they allow for a natural benchmark - if stock returns are log normally distributed, then an NCSKEW measure based on log changes should have a mean of zero. By putting a minus sign in front of the third moment, we are adopting the convention that an increase in NCSKEW corresponds to a stock having a more left-skewed distribution and then being more "crash prone".

The second measure we use is the down-to-up volatility (DUVOL) measure of crash likelihood from Chen et al. (2001), which is computed as follows. For each firm $j$ over a fiscal-year period $t$, we separate all the days with firm daily returns below the annual mean (“down” days) from those with firm returns above the annual mean ("up" days) and calculate the standard deviation for each of these sub-samples separately. The DUVOL measure is the log of the ratio of the standard deviation on the down days to the standard deviation on the up days. Thus, we have:

$$
\operatorname{DUVOL}_{j, t}=\log \left[\left(n_{u}-1\right) \sum_{\text {Down }} R_{j, t}^{2} /\left(n_{d}-1\right) \sum_{\text {Down }} R_{j, t}^{2}\right]
$$

where $n_{u}$ and $n_{d}$ are the number of up and down days, respectively. Again, the convention is that a higher value of this measure corresponds to a more left-skewed distribution and then being more "crash prone". 


\section{Measuring Information Disclosure Quality}

We use $R^{2}$ to measure information disclosure quality. $R^{2}$ measures firm’s synchronicity risk and has been received extensively as a proxy for information opacity. $R^{2}$ and residual returns are calculated from Capital Asset Pricing Model (single index model) regression:

$$
r_{j, t}=a_{j}+\beta R M_{t}+e_{j, t}
$$

where $r_{j, t}$ is the return on stock $j$ in day $t . R M_{t}$ is the value-weighted market index: Shanghai Securities Composite Index (SSCI).

$1-R^{2}$ is a natural measure of firm-specific volatility or (lack of) market synchronicity, but it is bounded between zero and one, which creates complications for empirical estimation. We follow common practice (e.g., Morck et al., 2000) in defining idiosyncratic risk using a logistic transformation of $R^{2}$, which can range from negative to positive infinity:

$$
r^{2}=\ln \left(\frac{R_{j, t}^{2}}{1-R_{j, t}^{2}}\right)
$$

Thus, a high value for $r^{2}$ indicates a low level of idiosyncratic risk and then a high level of opacity.

\section{Control Variables}

Following prior literatures, our control variables include SIZE, defined as the log of the market value of equity at the end of the fiscal year; $M B$, defined as the ratio of the market value of equity to the book value of equity measured at the end of the fiscal year; $L E V$, defined as the book value of all liabilities scaled by total assets, again measured at the end of the fiscal year; ROA, defined as net income divided by the book value of total asset. This measure is directly disclosed by annual financial statements; and finally HHI, defined as summation of the squares of first three major shareholders’ percentage.

\section{Research Models}

To test H1, we estimate the following four regressions that link our measures of crash risk to our proxies for information disclosure quality:

$$
\begin{aligned}
& \operatorname{NCSKEW}_{i, t}=a_{i}+\alpha_{1} r_{i, t}^{2}+\sum_{q=2}^{m} \alpha_{q}(q \text { th ControlVariables } i, t)+e_{i, t} \\
& \operatorname{DUVOL}_{i, t}=a_{i}+\alpha_{1} r_{i, t}^{2}+\sum_{q=2}^{m} \alpha_{q}\left(q \text { th ControlVariables } s_{i, t}\right)+e_{i, t}
\end{aligned}
$$

where $N C S K E W_{i, t}$ is the negative skewness of daily returns for firm $i$ in year $t$; and $D U V O L_{i, t}$ is the log of the ratio of the standard deviation on the down days to the standard deviation on the up days for firm $i$ in year $t$. $r^{2}$ is an indicator of idiosyncratic risk for firm $i$ in year $t$, which is defined by Equation (4). Equations (5) and (6) are estimated using panel data regression controlling year effect. H1 predicts a positive coefficient for $r^{2}$.

To test H2, we augment Equations (5) and (6) with more information disclosure assessments and the square of $r^{2}$ as follows:

$$
\begin{aligned}
& \operatorname{NCSKEW}_{i, t}=a_{i}+\alpha_{1} r_{i, t}^{2}+\alpha_{2}\left(r_{i, t}^{2}\right)^{2}+\sum_{q=2}^{m} \alpha_{q}(\text { qth ControlVariables } i, t)+e_{i, t} \\
& D_{U V O L} L_{i, t}=a_{i}+\alpha_{1} r_{i, t}^{2}+\alpha_{2}\left(r_{i, t}^{2}\right)^{2}+\sum_{q=2}^{m} \alpha_{q}(q \text { th ControlVariables } i, t)+e_{i, t}
\end{aligned}
$$


$\mathrm{H} 2$ predicts a positive association between information disclosure quality and crash risk. So, it indicates a positive coefficient for square of $r^{2}$.

\section{Empirical Analysis}

\section{Descriptive Statistics}

Panel A of Table 1 presents the descriptive statistics for all the variables used in the analyses based on the sample of firm-years with non-missing control variables; Panel B of Table 1 presents the correlation matrix. As seen in Panel A of Table 1, the mean value of NCSKEW is - 0.051 , which is much larger than zero suggesting that the sample of firm-years in our study is more crash prone.

Panel B of Table 1 shows that the two crash risk measures (i.e., NCSKEW and DUVOL) are highly positively correlated, with a ratio of 0.90 . Firm's synchronicity risk $r^{2}$ is also positively correlated with crash risk, as measured by NCSKEW and DUVOL. In addition, SIZE, MB, ROA, and HHI are all negatively correlated with crash risk and $L E V$ is positively correlated with crash risk.

Table 1

Descriptive Statistics and Correlations

\begin{tabular}{|c|c|c|c|c|c|c|c|c|}
\hline \multicolumn{9}{|c|}{ Panel A: Descriptive statistics } \\
\hline Variable & $N$ & Mean & Std. dev. & $25 \%$ & Median & $75 \%$ & Min. & Max. \\
\hline \multicolumn{9}{|c|}{ Crash risk measures } \\
\hline NCSKEW & 8,395 & -0.051 & 1.051 & -0.515 & 0.100 & 0.598 & -7.670 & 4.386 \\
\hline DUVOL & 8,395 & 0.044 & 0.570 & -0.255 & 0.095 & 0.410 & -4.403 & 3.462 \\
\hline \multicolumn{9}{|c|}{ Financial opacity measure } \\
\hline$r^{2}$ & 8,395 & -0.781 & 1.146 & -1.157 & -0.640 & -0.158 & -22.286 & 1.816 \\
\hline \multicolumn{9}{|c|}{ Control variables } \\
\hline$\overline{S I Z E}$ & 8,395 & 21.338 & 1.092 & 20.614 & 21.198 & 21.912 & 12.314 & 28.105 \\
\hline$M B$ & 8,395 & 4.825 & 3.542 & 2.122 & 3.479 & 6.336 & 1.486 & 12.799 \\
\hline$L E V$ & 8,395 & 0.444 & 0.219 & 0.279 & 0.447 & 0.604 & 0.033 & 1.240 \\
\hline$R O A$ & 8,395 & 0.033 & 0.070 & 0.012 & 0.037 & 0.065 & -0.351 & 0.201 \\
\hline HHI & 8,395 & 0.182 & 0.127 & 0.083 & 0.152 & 0.253 & 0.003 & 0.800 \\
\hline \multicolumn{9}{|c|}{ Panel B: Correlations } \\
\hline & NCSKEW & DUVOL & $r^{2}$ & SIZE & $M B$ & $L E V$ & $R O A$ & $H H I$ \\
\hline NCSKEW & 1.00 & & & & & & & \\
\hline DUVOL & $0.90^{* * *}$ & 1.00 & & & & & & \\
\hline$r^{2}$ & $0.53^{* * *}$ & $0.42^{* * *}$ & 1.00 & & & & & \\
\hline SIZE & -0.01 & $-0.05^{* * *}$ & $0.22^{* * *}$ & 1.00 & & & & \\
\hline$M B$ & $-0.38^{* * *}$ & $-0.33^{* * *}$ & $-0.50^{* * *}$ & $-0.23^{* * *}$ & 1.00 & & & \\
\hline$L E V$ & $0.04^{* * *}$ & 0.01 & $0.10^{* * *}$ & $0.33^{* * *}$ & $-0.09^{* * *}$ & 1.00 & & \\
\hline$R O A$ & $-0.18^{* * *}$ & $-0.18^{* * *}$ & $-0.07^{* * *}$ & $0.14^{* * *}$ & $0.23^{* * *}$ & $-0.45^{* * *}$ & 1.00 & \\
\hline HHI & $-0.03^{* *}$ & $-0.04^{* * *}$ & $0.05^{* * *}$ & $0.13^{* * *}$ & $-0.02^{*}$ & $-0.03^{* * *}$ & $0.09^{* * *}$ & 1.00 \\
\hline
\end{tabular}

\section{Main Regression Analysis}

H1 predicts that information opacity is positively related to stock price crash risk because it facilitates bad news hoarding. However, $\mathrm{H} 2$ predicts an opposite relation between them. Table 2 presents the multivariate regression analyses for testing $\mathrm{H} 1$ and $\mathrm{H} 2$. 
As shown in Table 2, $r^{2}$ is highly significant with a positive coefficient, implying that firms with greater information opacity are expected to have higher crash risk, which is consistent with H1. However, we examine potential nonlinearities in the relation between opacity and crash risk by adding the square of $r^{2}$ to the list of explanatory variables. Adding this quadratic term causes the coefficient on $r^{2}$ to change a little but the coefficient of square of $r^{2}$ is positive and highly statistically significant.

The nonlinear relation could arise from two sources. First, higher $r^{2}$ implies higher stock synchronicity and fewer firm-specific information publicly available. Possible bad news hoarding increases potential crash risk. If so, the relation between opacity and crash risk would be convex with a steeper reduction in crash risk at a higher value of opacity. Alternatively, we might observe thresholds beyond which opacity is already so low that additional information disclosure does not substantially upgrade information flow quality and in this area noise dominates information flow. Noise information enlarges volatility feedback effect and overreaction effect. If so, we would find a concave relation between $r^{2}$ (or opacity) and crash risk.

Table 2

Relation Between $r^{2}$ and Stock Price Crash Risk

\begin{tabular}{|c|c|c|c|c|c|c|}
\hline & \multicolumn{3}{|c|}{ NCSKEW } & \multicolumn{3}{|c|}{ DUVOL } \\
\hline & $\overline{(1)}$ & (2) & (3) & $\overline{(4)}$ & (5) & (6) \\
\hline \multirow{2}{*}{$r^{2}$} & $0.515^{* * *}$ & $0.428^{* * *}$ & $0.497^{* * *}$ & $0.246^{* * *}$ & $0.192^{* * *}$ & $0.237^{* * *}$ \\
\hline & (51.095) & (39.292) & (30.197) & (41.991) & $(30.495)$ & (24.883) \\
\hline \multirow{2}{*}{$S q r^{2}$} & & & $0.009^{* * *}$ & & & $0.006^{* * *}$ \\
\hline & & & (5.533) & & & (6.208) \\
\hline \multirow{2}{*}{ SIZE } & & $-0.088^{* * *}$ & $-0.095^{* * *}$ & & $-0.059^{* * *}$ & $-0.063^{* * *}$ \\
\hline & & $(-4.100)$ & $(-4.421)$ & & $(-4.721)$ & $(-5.083)$ \\
\hline \multirow{2}{*}{$M B$} & & $-0.075^{* * *}$ & $-0.070^{* * *}$ & & $-0.046^{* * *}$ & $-0.043^{* * *}$ \\
\hline & & $(-17.364)$ & $(-16.113)$ & & $(-18.481)$ & $(-17.102)$ \\
\hline \multirow{2}{*}{$L E V$} & & $0.585^{* * *}$ & $0.612^{* * *}$ & & $0.209^{* * *}$ & $0.227^{* * *}$ \\
\hline & & $(6.520)$ & (6.823) & & $(4.030)$ & $(4.370)$ \\
\hline \multirow{2}{*}{$R O A$} & & $-0.807^{* * *}$ & $-0.810^{* * *}$ & & $-0.694^{* * *}$ & $-0.696^{* * *}$ \\
\hline & & $(-4.401)$ & $(-4.430)$ & & $(-6.542)$ & $(-6.581)$ \\
\hline \multirow{2}{*}{$H H I$} & & $-0.543^{* * *}$ & $-0.560^{* * * *}$ & & $-0.323^{* * *}$ & $-0.334^{* * *}$ \\
\hline & & $(-3.732)$ & $(-3.856)$ & & $(-3.845)$ & $(-3.986)$ \\
\hline \multirow{2}{*}{ Constant } & $0.583^{* * *}$ & $2.740^{* * *}$ & $2.849^{* * *}$ & $0.357^{* * *}$ & $1.836^{* * *}$ & $1.907^{* * *}$ \\
\hline & (15.699) & (6.288) & (6.546) & (16.560) & (7.285) & $(7.578)$ \\
\hline Year fixed effect & Yes & Yes & Yes & Yes & Yes & Yes \\
\hline Firm fixed effect & Yes & Yes & Yes & Yes & Yes & Yes \\
\hline Observations & 8,395 & 8,395 & 8,395 & 8,395 & 8,395 & 8,395 \\
\hline$R$-squared & 0.467 & 0.504 & 0.506 & 0.374 & 0.423 & 0.427 \\
\hline Number of groups & 1,410 & 1,410 & 1,410 & 1,410 & 1,410 & 1,410 \\
\hline
\end{tabular}

Notes. $t$-statistics are shown in parentheses. ${ }^{* * * *}: p<0.01 ;{ }^{* * *}: p<0.05$; and ${ }^{*}: p<0.1$.

\section{Conclusion}

This study proposes a new hypothesis that information disclosure quality is nonlinear related to crash risk and finds Chinese stock market evidence to support it. We avoid possible endogeneity issue through focusing on the firms getting bad ratings and test the effect on its later impact on crash risk. These results are new and not entirely consistent with a theoretical model of crash risk based on information management. We identify one possible mechanism behind this nonlinear relation. Our study provides a new insight on the link between information disclosure quality and crash risk. 


\section{References}

An, H., \& Zhang, T. (2013). Stock price synchronicity, crash risk, and institutional investors. Journal of Corporate Finance, 21, 1-15.

Ball, R. (2009). Market and political/regulatory perspectives on the recent accounting scandals. Journal of Accounting Research, 47(2), 277-323.

Bartov, E., \& Bodnar, G. M. (1996). Alternative accounting methods, information asymmetry and liquidity: Theory and evidence. The Accounting Review, 71(3), 397-418.

Bhattacharya, U., Daouk, H., \& Welker, M. (2003). The world price of earnings opacity. The Accounting Review, 78(3), $641-678$.

Bleck, A., \& Liu, X. (2007). Market transparency and the accounting regime. Journal of Accounting Research, 45(2), 229-256.

Botosan, C. A. (1997). Disclosure level and the cost of equity capital. The Accounting Review, 72(3), 323-349.

Campbell, J. Y., \& Hentschel, L. (1992). No news is good news: An asymmetric model of changing volatility in stock returns. Journal of Financial Economics, 31(3), 281-318.

Chen, J., Hong, H., \& Stein, J. C. (200l). Forecasting crashes: Trading volume, past returns, and conditional skewness in stock prices. Journal of Financial Economics, 61(3), 345-381.

Coller, M., \& Yohn, T. L. (1997). Management forecasts and information asymmetry: An examination of bid-ask spreads. Journal of Accounting Research, 35(2), 181-191.

De Bondt, W. F. M., \& Thaler, R. (1985). Does the stock market overreact? Journal of Finance, 40(3), 793-805.

Dechow, P. M., Sloan, R. G., \& Sweeney, A. P. (1995). Detecting earnings management. The Accounting Review, 70(2), $193-225$.

Durnev, A., Morck, R., Yeung, B., \& Zarowin, P. (2003). Does greater firm-specific return variation mean more or less informed stock pricing? Journal of Accounting Research, 41(5), 797-836.

French, K. R., Schwert, G. W., \& Stambaugh, R. F. (1987). Expected stock returns and volatility. Journal of Financial Economics, 19(1), 3-29.

Hong, H., \& Stein, J. C. (2003). Differences of opinion, short-sales constraints, and market crashes. The Review of Financial Studies, 16(2), 487-525.

Hutton, A. P., Marcus, A. J., \& Tehranian, H. (2009). Opaque financial reports, $\mathrm{R}^{2}$, and crash risk. Journal of Financial Economics, 94(1), 67-86.

Jin, L., \& Myers, S. C. (2006). $R^{2}$ around the world: New theory and new tests. Journal of Financial Economics, 79(2), $257-292$.

Kim, J. B., Li, Y., \& Zhang, L. (2011a). Corporate tax avoidance and stock price crash risk: Firm-level analysis. Journal of Financial Economics, 100(3), 639-662.

Kim, J. B., Li, Y., \& Zhang, L. (2011b). CFOs versus CEOs: Equity incentives and crashes. Journal of Financial Economics, 101(3), 713-730.

Kothari, S. P., Shu, S., \& Wysocki, P. D. (2009). Do managers withhold bad news? Journal of Accounting Research, 47(1), 241-276.

Lang, M. H., \& Lundholm, R. J. (1993). Cross-sectional determinants of analyst ratings of corporate disclosures. Journal of Accounting Research, 31(2), 246-271.

Lang, M. H., \& Lundholm, R. J. (1996). Corporate disclosure policy and analyst behavior. The Accounting Review, 71(4), 467-492.

Leuz, C., \& Verrecchia, R. E. (2000). The economic consequences of increased disclosure. Journal of Accounting Research, 38, 91-124.

Mandelbrot, B. (1963). The variation of certain speculative prices. The Journal of Business, 36(4), 394-419

Miller, G. S. (2002). Earnings performance and discretionary disclosure. Journal of Accounting Research, 40(1), 173-204.

Morck, R., Yeung, B., \& Yu, W. (2000). The information content of stock markets: Why do emerging markets have synchronous stock price movements? Journal of Financial Economics, 58(1-2), 215-260.

Piotroski, J. D., \& Roulstone, B. T. (2004). The influence of analysts, institutional investors, and insiders on the incorporation of market, industry, and firm-specific information into stock prices. Accounting Review, 79(4), 1119-1151.

Roll, R. (1988). $R^{2}$. Journal of Finance, 43(3), 541-566.

Romer, D. (1993). Rational asset-price movements without news. American Economic Review, 83(5), 1112-1130. 